Oikos 122: 1187-1194, 2013

doi: $10.1111 / j .1600-0706.2012 .00245 . x$

(C) 2013 The Authors. Oikos (C) 2013 Nordic Society Oikos

Subject Editor: Ulrich Brose. Accepted 9 November 2012

\title{
Resource tracking in marine parasites: going with the flow?
}

\author{
Ross M. Thompson, Robert Poulin, Kim N. Mouritsen and David W. Thieltges \\ R. M. Thompson (ross.thompson@canberra.edu.au), Inst. for Applied Ecology, Univ. of Canberra, Bruce ACT 2601, Australia, Australian \\ Centre for Biodiversity and School of Biological Sciences, Monash Univ., Clayton, VIC3800, Australia. - R. Poulin, Dept of Zoology, \\ Univ. of Otago, PO Box 56, Dunedin, New Zealand. - K. N. Mouritsen, Dept of Bioscience, Marine Ecology, Ole Worms Allé 1, DK-8000 \\ Aarhus C, Denmark. - D. W. Thieltges, NIOZ Royal Netherlands Inst. for Sea Research, PO Box 59, NL-1790 AB Den Burg Texel, \\ the Netherlands.
}

\begin{abstract}
Understanding how diversity interacts with energy supply is of broad ecological interest. Most studies to date have investigated patterns within trophic levels, reflecting a lack of food webs which include information on energy flow. We added parasites to a published marine energy-flow food web, to explore whether parasite diversity is correlated with energy flow to host taxa. Parasite diversity was high with 36 parasite taxa affecting 40 of the 51 animal taxa. Adding parasites increased the number of trophic links per species, trophic link strength, connectance, and food chain lengths. There was evidence of an asymptotic relationship between energy flowing through a food chain and parasite diversity, although there were clear outliers. High parasite diversity was associated with host taxa which were highly connected within the food web. This suggests that energy flow through a taxon may favour parasite diversity, up to a maximal value. The evolutionary and energetic basis for that limitation is of key interest in understanding the basis for parasite diversity in natural food webs and thus their role in food web dynamics.
\end{abstract}

The relationship between diversity and ecosystem functions such as productivity has been, and remains, one of the fundamental areas of research in ecology. Positive relationships between diversity and productivity were first proposed in the 1940s (Lindeman 1942), suggesting that higher basal productivity promoted higher predator diversity. This was formalized into the 'productivity hypothesis' (Pimm 1982), which has been much explored across studies ranging from bacteria in microcosms (Jenkins et al. 1992, Kaunzinger and Morin 1998, Warren and Weatherby 2006) to large scale ecological manipulations of productivity (Nakano et al. 1999, Wallace et al. 1997), detailed analyses of field data (Monkkonen et al. 2006, Thompson and Townsend 2005a), and meta-analyses (Field et al. 2009).

Donor-controlled dynamics would suggest that diversity in the consumer trophic level is a function of the energy available from the resource trophic level. Lindeman's (1942) classic study belongs within this group, suggesting that increased productivity promotes increased diversity through additional trophic levels (lengthening of food chains). There have been a number of studies which have found a positive correlation between basal productivity and consumer diversity (Thompson and Townsend 2005a) although the pattern is not universal (Arim et al. 2007). A simpler donor-controlled mechanism would be that higher resource productivity provides additional energetic niche space, allowing increased diversity within the consumer trophic level (Hashmi and Causey 2008). In this case diversity should be directly related to productivity in adjacent trophic levels.

Exploring the relationships between energy flows and diversity has traditionally been complicated by a lack of suitable data sets which incorporate both diversity and energy flows. Food web studies occupy the junction between studies of diversity and ecosystem processes, in that they represent patterns of species diversity (the nodes) and movements of energy (connections between nodes) (Thompson et al. 2012). Although describing such trophic networks has a rich history (summarized by Pascual and Dunne 2004, Pimm 1982), it is only in the last decade that sufficient rigor has been applied in terms of taxonomic resolution and sampling effort that we can be confident that the resulting food webs reflect biological reality rather than sampling artifacts. There is now a body of highly resolved food webs which have proven useful in testing fundamental ecological theory (Thompson et al. 2007, 2012). These food webs are greatly improved in terms of the degree of taxonomic resolution (Thompson and Townsend 2000), inclusion of spatial and temporal variability (Martinez 1993, Thompson and Townsend 2005b), and sampling of formerly poorly represented groups (Schmid-Araya and Schmid 2000). The inclusion of parasites into highly resolved food webs has been the most recent challenge in food web ecology (Lafferty et al. 2008). Research has shown that including parasites in food webs can dramatically alter perceptions of food web topology (Huxham et al. 1996, Thompson et al. 2005, Amundsen et al. 2009). For example, inclusion of parasites 
has been shown to lengthen food chains, increase internal connectance and alter predator to prey ratios substantively (Huxham et al. 1996). There remains however, the challenge of integrating parasites into food webs which reflect dynamics (weighted flows of energy) rather than simply topology (binary indications of energy flow). Addressing questions of the relationship between diversity and ecosystem function in real food webs requires food webs which are not only highly resolved and inclusive, but also include weighted measures of trophic links between all components of the food web.

The availability of food webs with weighted measures of energy flow which also include parasites provides us with an opportunity to explore productivity/diversity relationships in very closely coupled trophic levels. Food chains which supply larger amounts of energy might be expected to be 'targeted' by parasites through evolutionary time, leading to a higher diversity of parasite species in taxa which are in high energy food chains. Higher energy supplies of certain food chains might simply support higher numbers of parasites. This will be valid for all types of parasites. However, in trophically transmitted parasites (those transmitted by ingestion) higher energy flows might also increase chances for parasites to be transmitted. Parasites may either target these high flow nodes or simply accumulate there at higher rates. Productivity may also through evolutionary time favour speciation; it has been proposed that rates of parasite evolution may be higher when systems are more productive (Lopez-Pascua and Buckling 2008). It is not only the total amount of energy flowing into a node that can determine how many parasite species will exploit that node, however. For trophicallytransmitted parasites, the number of paths of energy (i.e. links) flowing into a node may be more important. These parasites can be highly specific to particular intermediate host species, and only definitive hosts at higher trophic levels with broad diets (many links) are likely to acquire diverse parasite communities (Poulin and Morand 2000, Poulin and Rohde 1997). Thus, the position of a node within the network can matter as much, if not more, than the amount of energy it receives. Using a modified version of a very highly resolved food web from the Sylt-Rømø Bight, in the Wadden Sea we sought to explore three fundamental questions:

1. Are parasite transmission routes preferentially associated with food chains that have the highest flows of energy?

2. Does parasite diversity peak in hosts with the highest energy flow?

3. Does parasite diversity correlate with how highly connected hosts are in food webs?

We predict that parasite diversity will be highest in hosts that receive the most energy in a food web, i.e. those that are embedded in food chains with high energy flow and are at positions in the food web with high flow through of energy.

\section{Methods}

The food web used for the analysis is a highly resolved food web from the Sylt-Rømø Bight in the Wadden Sea, northern Europe (Baird et al. 2004). This is an earlier version of the larger (but not flow-weighted) food web recently compiled by Thieltges et al. (2011). The flow food web used here has been described over time using detailed studies of all of the food web compartments. Briefly, it is based on autotrophic production by phytoplankton, macrophytes and microphytobenthos, with benthic sub-webs of invertebrates channeling energy to fish and seabirds (see Baird et al. 2004 for details). The food web is unique in that it is highly taxonomically resolved (particularly for birds and fish), and includes weighted flows of energy based on productivity and biomass measurements. To this published food web we added a parasite-host sub-web. Information on parasites and their life cycles was compiled from the literature, following a thorough search of studies published on parasites in the Wadden Sea fauna, and in that of adjacent seas (Supplementary material Appendix 1). In addition, we used unpublished data and local expert knowledge to complement life cycle information. The parasites and their transmission paths were then mapped onto the web.

To facilitate analysis, all non-feeding compartments were removed. Bacteria were considered basal (curtailing energy looping through the microbial loop/detritus/decomposition pathway). All taxa in the food web were classified as basal (non-consuming), intermediate (both consume other taxa and are consumed) or top (not consumed). Flow based trophic position (TP) was calculated for all non-parasitic taxa from the weighted matrix of energy flows (Williams and Martinez 2004). This attributes all basal components a trophic position of 0 . Trophic positions of consumers are calculated as the weighted average of all of the trophic positions of all items consumed. Integer values for TP indicate species feeding at a defined trophic level $(1=$ herbivore, $2=$ primary predator, $3=$ secondary predator, etc.) (Thompson et al. 2007).

A range of standard food web attributes was calculated from the food web, first without the parasites included, then with the parasite community included. Attributes calculated were; total number of taxa (S), total number of trophic links (L), links per species (L/S) summed link strength, average link strength, simple connectance (Cs), parasite adjusted connectance $(\mathrm{Cp})$, average food chain length and maximum food chain length. We excluded predator-parasite links as suggested by Lafferty et al. (2006). Summed link strength (the sum of all the link weights in the matrix) and average link strength (summed link strength divided by the number of taxa in the web) were calculated from the raw data matrices. Connectance was calculated in two ways. Simple connectance $\left(\mathrm{C}_{\mathrm{s}}\right)$ (Hall and Raffaelli 1991) is the number of links that do occur in a matrix $(L)$ divided by the total number of links if all links were possible (calculated as the square of the number of nodes, $S)$, and is calculated as $L /\left(S^{2}\right)$. Realised connectance (Thompson and Townsend 2005b) is the proportion of food web links which actually occur divided by the number that could conceivably occur. This excludes from the denominator of the connectance formula links from basal taxa to basal taxa and parasites to basal taxa. Formally, realised connectance $\left(\mathrm{C}_{\mathrm{R}}\right)$ is calculated as $L /[(S \times S)-(b \times S)-(p \times b)]$, where $b$ is the number of basal species and $p$ is the number of parasite species. These 
modifications make changes in connectance biologically relevant, as opposed to being simply an artefact of the number of non-feeding or parasitic species (Lafferty et al. 2006).

Average and maximum food chain lengths were calculated using network analysis tools. UCINET 6.0 (Borgatti et al. 2002) was used to handle the data matrices and make them available to Pajek 0.96 (Batagelj and Mrvar 1998) for calculation of chain lengths.

To ascertain factors relating to parasite diversity at each node, the number of parasites infecting each node was calculated from the data matrix. Attributes reflecting energy flows to each parasitised node were then calculated. Energy flow to each node was calculated in two ways. Firstly, the weighted links from the node's immediate resources were summed ('inlink weight'). Secondly, the total of all weighted links in all trophic interactions in the food chain leading to each node was calculated ('total chain weight'). Network position of each host was then described using measures of centrality calculated in Pajek 0.96 (Batagelj and Mrvar 1998), following the approach of Chen et al. (2008). Closeness centrality indicates the position of a node in a network relative to prey species, and is considered to reflect a wider diet range and a better capacity to accumulate resources from species at lower trophic levels (Chen et al. 2008). A low value of closeness centrality indicates a node which is strongly linked to other nodes. Betweenness centrality indicates the position in the network relative to consumers, and is considered to reflect vulnerability to predators (Chen et al. 2008). A node with high betweenness centrality is important in that it mediates many indirect interactions between pairs of nodes. Both centrality measures were calculated for the food web with the parasite subweb excluded. Inlink weight, total chain weight, closeness centrality and betweenness centrality for each node were plotted against the parasite diversity for that node.
To visualize the food web, the matrix was plotted using Netdraw within UCINET 6 (Borgatti et al. 2002). The network graph was then modified by hand to generate a food web arranged by trophic position (as calculated above), and superimposed with the parasite diversity of each node.

\section{Results}

The parasite-inclusive version of the Sylt-Rømø Bight food web included 94 taxa (Fig. 1, Table 1). Taxonomic resolution was high, with $77 \%$ of nodes identified to species level. Five nodes were classified as basal, with primary production being derived from both planktonic and benthic sources. Of the animal taxa present in the food web 22 were clearly primary consumers, 24 could be classified as predators and 5 as omnivores (Fig. 1). There were 15 top predators if parasites were excluded from the food web. Thirty-six parasitic taxa were included in the food web, primarily trematodes (Table 1). Of the 51 free-living animal taxa in the food web, only 11 were not recorded as being parasitised, and only one predatory species was not parasitised. Parasite diversity ranged from 1 to 23 taxa, with an average diversity of 9.7 taxa per host $(\mathrm{SD}=7.6)$.

Inclusion of the parasite sub-web in the food web altered food web attributes considerably (Table 2). Number of trophic links, links per species, summed trophic link strength and average link strength per species were all higher in the parasite-inclusive food web. Connectance was greater in the food web after the inclusion of parasites; adjusting connectance to take into account the limited number of possible links to parasites (parasitised connectance) made the detected increase larger. Average and maximum food chain lengths were slightly increased by including the parasite sub-web (Table 2). As these attributes

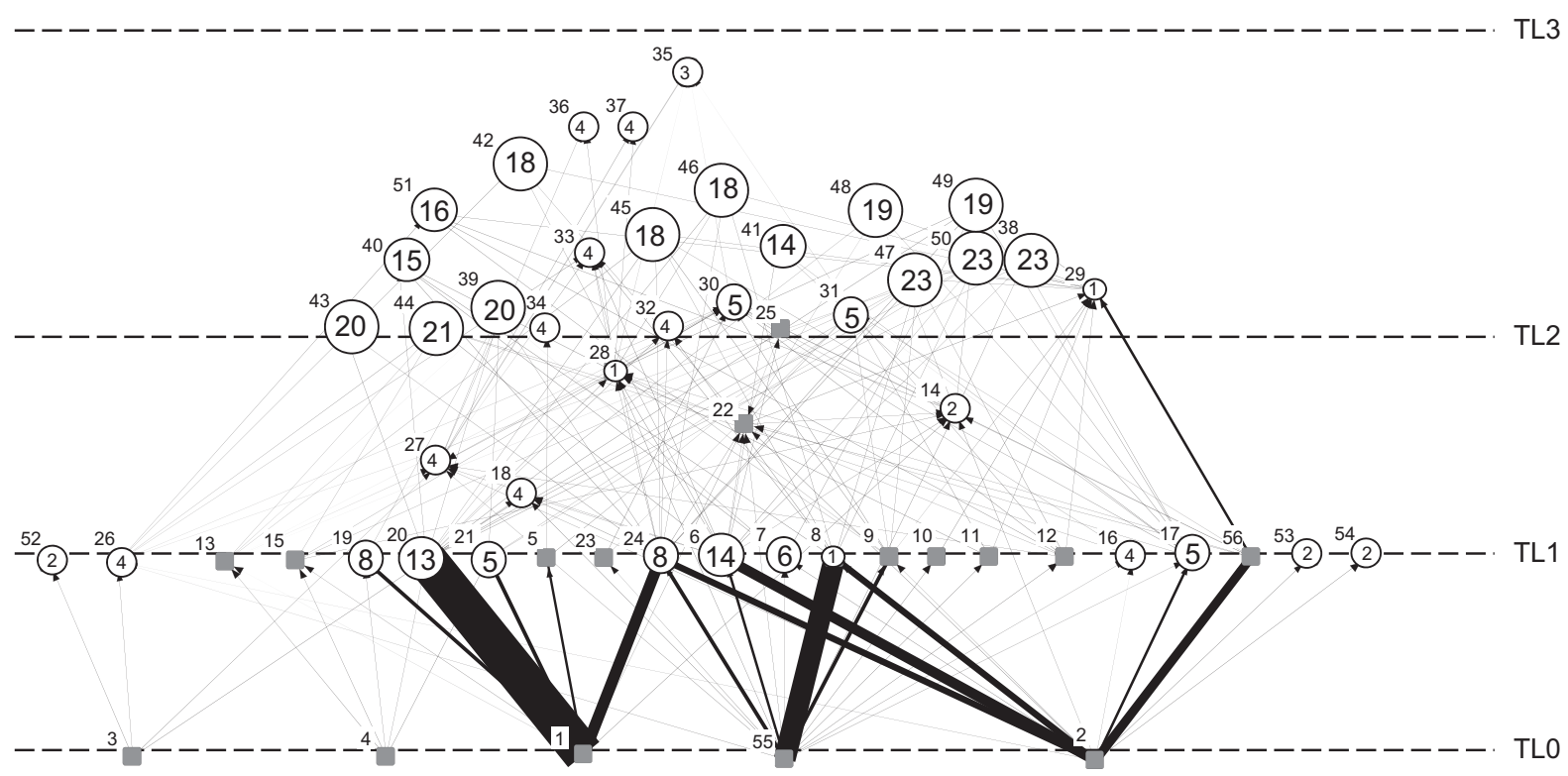

Figure 1. Sylt-Rømø Bight food web, showing weighted links (thickness of connecting lines) between nodes ( $\mathbf{\square})$. Numbers which are not circled indicate the taxa represented by each node (see Table 1 for codes). Taxa are arranged by trophic position (see methods for details), with trophic levels indicated by dotted lines $($ TL $0=$ basal components, TL1 $=$ herbivore, TL2 $=$ primary predator, TL3 $=$ secondary predator). Numbers in circles indicate the diversity of parasites infecting each node, with the size of circles increasing with diversity. 
Table 1. Taxa present in the Sylt-Rømø Bight food web. Numbers indicate location on the food web graph shown in Fig. 1.

\begin{tabular}{|c|c|}
\hline \multicolumn{2}{|l|}{ Basal } \\
\hline 1 & Phytoplankton \\
\hline 2 & Microphytobenthos \\
\hline 3 & Macrophytes \\
\hline 4 & Free-living bacteria \\
\hline \multicolumn{2}{|c|}{ Zooplankton } \\
\hline 5 & Zooplankton \\
\hline \multicolumn{2}{|c|}{ Macrobenthos } \\
\hline 6 & Hydrobia ulvae \\
\hline 7 & Littorina littorea \\
\hline 8 & Arenicola marina \\
\hline 9 & Scoloplos armiger \\
\hline 10 & Capitellidae \\
\hline 11 & Oligochaeta \\
\hline 12 & Heteromastus filiformis \\
\hline 13 & Lanice conchilega \\
\hline 14 & Nereis diversicolor \\
\hline 15 & Pygospio elegans \\
\hline 16 & Corophium arenarium \\
\hline 17 & Corophium volutator \\
\hline 18 & Gammarus spp. \\
\hline 19 & Mytilus edulis \\
\hline 20 & Cerastoderma edule \\
\hline 21 & Mya arenaria \\
\hline 22 & Small polychaetes \\
\hline 23 & Tharyx killariensis \\
\hline 24 & Macoma balthica \\
\hline 25 & Phyllodocidae \\
\hline 26 & Small crustaceans \\
\hline 27 & Carcinus maenas \\
\hline 28 & Crangon crangon \\
\hline 29 & Nephthys spp. \\
\hline \multicolumn{2}{|c|}{ Fishes } \\
\hline 30 & Pomatoschistus microps \\
\hline 31 & Pomatoschistus minutus \\
\hline 32 & Pleuronectes platessa \\
\hline 33 & Pleuronectes flesus \\
\hline 34 & Clupea harengus \\
\hline 35 & Merlangius merlangus \\
\hline 36 & Gadus morrhua \\
\hline 37 & Myoxocephalus scorpio \\
\hline \multicolumn{2}{|r|}{ 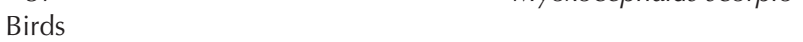 } \\
\hline 38 & Tadorna tadorna \\
\hline 39 & Somateria mollissima \\
\hline 40 & Haematopus ostralegus \\
\hline 41 & Recurvirostra avosetta \\
\hline 42 & Pluvialis apricaria \\
\hline 43 & Calidris canutus \\
\hline 44 & Calidris alpine \\
\hline 45 & Limosa lapponica \\
\hline 46 & Numenius arquata \\
\hline 47 & Larus ridibundus \\
\hline 48 & Larus canus \\
\hline 49 & Larus argentatus \\
\hline 50 & Other birds \\
\hline 51 & Anas platyrhynchos \\
\hline 52 & Anas acuta \\
\hline 53 & Anas penelope \\
\hline 54 & Branta bernicla \\
\hline \multicolumn{2}{|c|}{ Benthic microfauna } \\
\hline 55 & Sediment bacteria \\
\hline 56 & Meiobenthos \\
\hline \multicolumn{2}{|c|}{ Trematodes } \\
\hline 60 & Microphallus claviformis \\
\hline 61 & Microphallus pygmaeus \\
\hline
\end{tabular}

(Continued)
Table 1. (Continued).

\begin{tabular}{|c|c|}
\hline 62 & Microphallus pirum \\
\hline 63 & Microphallus oocysta \\
\hline 64 & Maritrema subdolum \\
\hline 65 & Maritrema species 15 \\
\hline 66 & Levinseniella brachysoma \\
\hline 67 & Himasthla elongata \\
\hline 68 & Himasthla continua \\
\hline 69 & Himasthla interrupta \\
\hline 70 & Cryptocotyle concavum \\
\hline 71 & Cryptocotyle jejuna \\
\hline 72 & Cryptocotyle lingua \\
\hline 73 & Cercaria ephemera \\
\hline 74 & Cercaria lebouri \\
\hline 75 & Psilostomum brevicolle \\
\hline 76 & Psilochasmus aglyptorchis \\
\hline 77 & Deropristis inflata \\
\hline 78 & Renicola roscovita \\
\hline 79 & Parvatrema minutus \\
\hline 80 & Gymnophallus gibberosus \\
\hline 81 & Gymnophallus choledochus \\
\hline 82 & Gymnophalloides macomae \\
\hline 83 & Parvatrema affinis \\
\hline 84 & Monorchis parvus \\
\hline 85 & Bucephalus minimus \\
\hline 86 & Podocotyle atomon \\
\hline \multicolumn{2}{|c|}{ Turbellaria } \\
\hline 87 & Paravortex cardii \\
\hline \multicolumn{2}{|c|}{ Nematodes } \\
\hline 88 & Nematoda sp. \\
\hline \multicolumn{2}{|c|}{ Crustacean parasites } \\
\hline 89 & Mytilicola intestinalis \\
\hline 90 & Copepoda species 1 \\
\hline 91 & Copepoda species 2 \\
\hline 92 & Sacculina carcini \\
\hline \multicolumn{2}{|c|}{ Acanthocephala } \\
\hline 93 & Profilicollis botulus \\
\hline \multicolumn{2}{|c|}{ Cestodes } \\
\hline 94 & Cestoda species 2 \\
\hline
\end{tabular}

do not simply scale with food-web size (Dunne et al. 2002) these changes are not likely to be a result of simply increasing the size of the food web, although that possibility cannot be discounted.

There was evidence of an asymptotic relationship between parasite diversity and total food chain link strength (total amount of energy flowing through a food chain (Fig. 2A). There was no evidence of higher parasite diversity associated with inlink strength (amount of energy flowing in to the host) (Fig. 2B). However there were six

Table 2. Food web attributes for the Sylt-Rømø Bight food web with and without the inclusion of the parasite sub web. For definitions, see methods.

\begin{tabular}{lcc}
\hline & $\begin{array}{c}\text { Parasites } \\
\text { excluded }\end{array}$ & $\begin{array}{c}\text { Parasites } \\
\text { included }\end{array}$ \\
\hline Total number of taxa $(\mathrm{S})$ & 56 & 92 \\
Number of links $(\mathrm{L})$ & 190 & 570 \\
Number of links per species $(\mathrm{L} / \mathrm{S})$ & 3.39 & 6.20 \\
Summed link strength & 743.45 & 1746.25 \\
Average link strength & 13.28 & 18.98 \\
Simple connectance $\left(\mathrm{C}_{\mathrm{s}}\right)$ & 0.061 & 0.067 \\
Parasite adjusted connectance $\left(\mathrm{C}_{\mathrm{p}}\right)$ & 0.067 & 0.087 \\
Average food chain length & 1.612 & 1.737 \\
Maximum food chain length & 3 & 4 \\
\hline
\end{tabular}



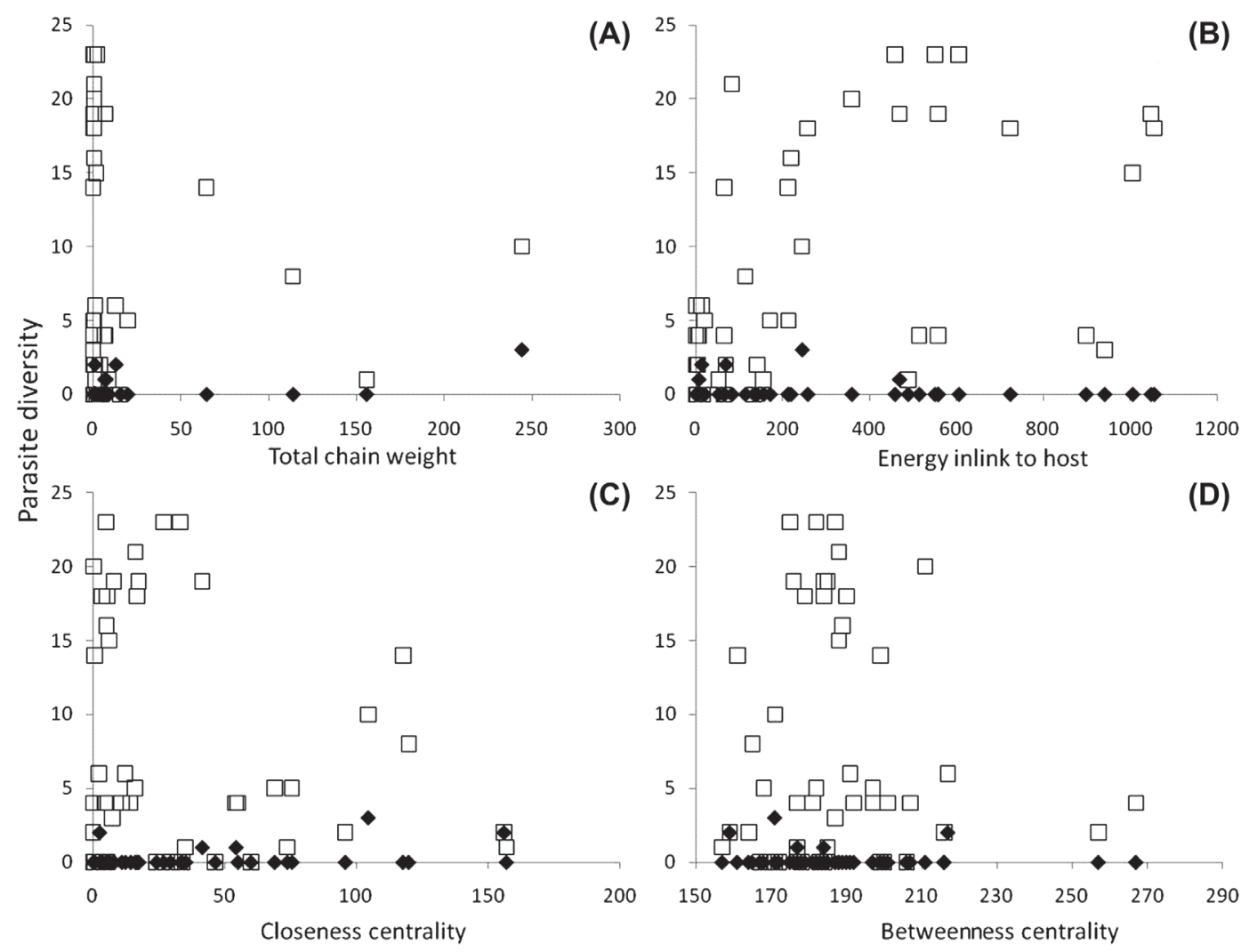

Figure 2. Relationships between parasite diversity (expressed as number of parasites linking to a food web node) and: (A) summed food chain weight, the total amount of energy flowing through a food chain; (B) inlink weight, the amount of energy flowing into the food web node; (C) closeness centrality, reflecting distance from other nodes in the network; and (D) betweenness centrality, reflecting importance in mediating indirect interactions between pairs of nodes. Trematode parasites are shown as white squares, with all other parasite types shown as black diamonds.

clear outliers which were involved in chains with large amounts of energy flowing through them, but had relatively low parasite diversity. These species were the brown shrimp Crangon crangon and five species of fish; European plaice and flounder, Pleuronectes platessa and P. flesus, whiting Merlangius merlangus, cod Gadus morrhua and sculpin Myoxocephalus scorpio.

There was a general pattern that the highest parasite diversity nodes were associated with low values of closeness centrality; no node with parasite diversity of $>15$ had a closeness value of $>50$ (Fig. 2C). This shows that hosts which had the highest parasite diversity were generally highly connected to other nodes in the food web. There was no evidence of strong relationship between parasite diversity and betweenness centrality, although there was some evidence that high parasite diversity primarily occurred in nodes with low-intermediate values of betweenness (Fig. 2D) suggesting the vulnerability to predators was not strongly associated with diversity of parasites.

There was no evidence of differing relationships when different types of parasites were considered separately. Trematodes numerically dominated the data and were the main drivers of all patterns (Fig. 2). Nor were there any changes to the patterns when we considered particular parasite lifestyles or single trophic levels within the food web. It appears that the patterns seen here are general to the food web.

\section{Discussion}

Parasites are ubiquitous in natural systems, but it is only recently that they have been effectively incorporated into detailed analyses of food webs (Lafferty et al. 2008). Here we have integrated the parasite sub-web with an existing published food web from the Sylt-Rømø Bight. Consistent with previous parasite-inclusive food webs (Huxham et al. 1996, Lafferty et al. 2006, Thompson et al. 2005) we found parasites had a major effect on the topology of the food web. In the Sylt-Rømø Bight food web numbers of trophic links were greatly increased, food chains lengthened and connectivity increased.

Of particular interest in this analysis was the relationship between parasite diversity at a node and the amount of energy passing through that node. If productivity does indeed generate or maintain diversity, then it might be expected that species that have large volumes of energy passing through them would also have the highest parasite diversity. Patterns might be expected to be particularly strong for parasites, if the underlying causes of such relationships are metabolic in origin (Hawkins et al. 2007), as the host is a relatively closed habitat isolated from other factors such as disturbance. While there was some hint of a saturating relationship between summed food chain weight (representing the total energy flowing in a 
food chain) and parasite diversity, there were notable outliers. A number of taxa were members of chains with large flows of energy, but had relatively low parasite diversity. This might partly be explained by underestimated parasite diversity resulting from sampling artifacts. While trematodes are the best studied group in intertidal systems due to their relatively easy identification in intermediate hosts (Mouritsen and Poulin 2002), the presence and life cycles of other parasites likes cestodes and nematodes are less known, particularly for fish. In addition, fishes are generally not well integrated in intertidal parasite-hosts systems where birds prevail as definitive hosts for trematodes (Mouritsen and Poulin 2002). However, it might also be that for some species like whiting, cod and sculpin, the relatively low parasite diversity in chains with large flows of energy reflects the fact that they occur high in food chains that have large amounts of energy flowing through the lower portions of the chain. This energy may not be effectively reaching the fish predators at the top of the chain due to inefficiencies of energy transfers. Nevertheless, there is some support for further investigation of the role of donor controlled processes in driving parasite diversity.

Our approach to investigating the relationship between productivity and parasite diversity has some significant limitations. Productivity has been proposed to increase rates of parasite evolution (Lopez-Pascua and Buckling 2008). The lack of association between parasite diversity and the amount of energy flowing through a food chain or into a host node may reflect other evolutionary constraints. Some associations between hosts and parasites have ancient phylogenetic histories, and parasites show strong coevolutionary ties with particular host taxa, whether or not the latter happen to be part of strong energy flows in a web (Brooks 1988, Poulin 2007a). Compatibility between a parasite and potential host species depends on behavioural, morphological, and immunological factors (Adamson and Caira 1994, Poulin 2007b). Thus although natural selection would favor parasites that follow the strongest energy flows in a food web, constraints acting on host specificity may pose insurmountable obstacles. This may in part explain the observed outliers discussed above (members of chains with large flows of energy, but relatively low parasite diversity). Birds prevail as definitive hosts in intertidal systems (Mouritsen and Poulin 2002) and fish may harbour lower parasite diversity than expected based on energy flows because of host specificity constraints.

Another limitation is that estimates of energy flow to particular nodes are fraught with difficulty, and can be highly variable between individuals and through time. If variability in energy flow is large at an individual to individual level, this may act against a parasite's ability to evolve to track resources through time. Similarly, temporal variability in patterns of energy flow may create resource limitation which prevents high levels of diversity persisting in a consumer. Perhaps parasite diversity depends more on low variance than on high amounts of energy passing through a node. Many of these constraints could be addressed by studying similar food webs along productivity gradients. It would then be expected that at a whole food web level parasite diversity would be higher in more productive environments.
Similarly, our estimates of parasitisation are based on a literature review and may not be sufficient to include all of the parasites in the food web. Parasite richness increases with the number of hosts that have been inspected for parasites. Parasite links based on literature review alone, and not systematic sampling, may bias results as some taxa will have been studied more intensively than others. In addition, well-studied hosts (or hosts that support a high degree of energy flow) may be more likely to have received more attention to their diet and predators, making them seem more connected in a food web compared to more obscure species. In this system we were able to complement information from the literature with information on parasite richness in the intermediate hosts (e.g. molluscs, crustaceans, polychaetes, some fish species) from actual surveys that have systematically screened hosts for parasites. As most parasites have complex life cycles which involve just these taxa as intermediate hosts, we have a good understanding of what parasites are present in a system. As a result the food web is likely to be quite robust to sampling bias, but may overestimate the actual parasite richness in some host species, without any systematic bias. We are unlikely to have sampled all of the parasites, but we will have sampled the majority, given the large number of detailed studies which have taken place in this region. We did not consider it wise to bring in literature from outside of the study area, as one of the strengths of this study is that it is clearly spatially delimited. As the parasites in this system mainly cycle in the intertidal, the part of the food web is probably quite robust but potential parasites moving in via large mobile consumers (fish and birds) may not all be included. This is a potential for all food web studies, which must necessarily be spatially delimited in some way.

The food web is the long-term product of systematic sampling of all free-living taxa in the system coupled with estimates of energy flow among them. In parallel, the few fish species in this system, as well as many birds and all large species of molluscs and crustaceans, have all been individually targeted by parasitological studies in the past (Supplementary material Appendix 1), making the Wadden Sea one of the best-studied marine ecosystems in the world. Although the exact number of individuals examined for parasites cannot be retrieved from most of the sources used in order to test for a relationship between parasite richness and host sampling effort, the lack of published reports of new host-parasite associations in the Wadden Sea over the past several years suggests that present knowledge of parasitism in this system is as exhaustive as it can get (without molecular prospecting for cryptic species).

Our second approach to relating parasite diversity to energy flows through the Sylt-Rømø Bight food web involved using a network analytic approach. Chen et al. (2008), by studying relationships between parasite diversity and network position of hosts, found that host species with high parasite diversity tended to have low values of closeness centrality. Low values for closeness centrality are associated with a wide diet range and an ability to readily accumulate resources from species at lower trophic levels (Chen et al. 2008). This supports the concept that donor control may influence parasite diversity. Our results for the 
Sylt-Rømø Bight food web are consistent with Chen et al.'s (2008) results, with the highest parasite diversity nodes tending to be close to other nodes in the food web. Chen et al. (2008) also found a weak positive relationship between parasite diversity and betweenness centrality. High values for betweenness centrality indicate involvement in a large number of food chains and a high vulnerability to predators (Chen et al. 2008). In our food web there was no evidence of a positive relationship between diversity and betweenness; rather there was a general absence of parasites in the taxa with the highest values for betweenness centrality.

While the food web reported here is by far the most detailed flow food web to incorporate information on parasites, it does have limitations. Using quantitative data on host use by parasites (i.e. percent of the host population infected, or mean number of parasite individuals per host individual) instead of binary presence/absence data, could allow greater resolution of the link between energy flow and parasite transmission. Also, parasites vary greatly in body sizes (i.e. cestodes can be several orders of magnitudes larger than trematodes), and the numerical dominance of a large species in a host can constrain parasite diversity. If data were available, using parasite abundance or biomass to compute diversity indices other than species richness might reveal patterns missed in the present analyses. In order to make the food web tractable for the food web analysis, simplifications were made which may have altered the outcomes. It is possible that our maps may not reflect true energy flows in the food web because they omit detrital flows (Halnes et al. 2007). Ideally we would integrate actual measures of energy flow through time (e.g. stable isotope analysis and mass balance energy models) with the topological maps of energy flows provided by food webs. We are not aware of any data set internationally which would allow an analysis of that type.

Our results provide further illustration of the important topological role of parasites in food webs. We find preliminary evidence for a relationship between resource supply and parasite diversity (donor control), but also for a role of network position in determining diversity of parasite communities. It appears that high parasite diversity is associated with hosts which are highly connected within the food web, and which receive higher amounts of energy flow. However there are clearly other factors which act to limit total parasite diversity (i.e. the relationship is asymptotic) and allow some taxa to have low parasite diversity despite high amounts of energy flow. As with relationships between energy supply and diversity in non-parasite food webs, factors such as ecosystem size (in this case competition for space within hosts) and disturbance (a variety of factors including host defenses against parasites and predation on hosts) may have important interactions with energy supply in driving patterns of diversity.

Acknowledgements - Thanks to Martin Hemberg for use of his code for calculating trophic position. DWT acknowledges support from a personal grant (Th 1361/1-1) from the German Research Foundation (DFG). RT was funded in part by an ARC Future Fellowship (ARC-FT110100957). This work was conducted as part of the Parasites and Food Webs Working Group supported by the National Center for Ecological Analysis and Synthesis (NCEAS), a center funded by NSF (grant no. DEB-0553768), the Univ. of California, Santa Barbara, and the State of California.

\section{References}

Adamson, M. L. and Caira, J. N. 1994. Evolutionary factors influencing the nature of parasite specificity. - Parasitology 109: S85-S95.

Amundsen, P. A. et al. 2009. Food web topology and parasites in the pelagic zone of a subarctic lake. - J. Anim. Ecol. 78: 563-572.

Arim, M. et al. 2007. On the relationship between productivity and food chain length at different ecological levels. - Am. Nat. 169: 62-72.

Baird, D. et al. 2004. Energy flow of a boreal intertidal ecosystem, the Sylt-Rømø Bight. - Mar. Ecol. Prog. Ser. 279: 45-61.

Batagelj, V. and Mrvar, A. 1998. Pajek: program for large network analysis. - Connections 21: 47-57.

Borgatti, S. P. et al. 2002. Ucinet for Windows: software for social network analysis. - Analytic Technologies, Harvard, USA.

Brooks, D. R. 1988. Macroevolutionary comparisons of host and parasite phylogenies. - Annu. Rev. Ecol. Syst. 19: 235-259.

Chen, H. et al. 2008. Network position of hosts in food webs and their parasite diversity. - Oikos 117: 1847-1855.

Dunne, J. A. et al. 2002. Food-web structure and network theory: the role of connectance and size. - Proc. Natl Acad. Sci. USA 99: 12917-12922.

Field, R. et al. 2009. Spatial species-richness gradients across scales: a meta-analysis. - J. Biogeogr. 36: 132-147.

Hall, S. J. and Raffaelli, D. 1991. Food-web patterns - lessons from a species-rich web. - J. Anim. Ecol. 60: 823-842.

Halnes, G. et al. 2007. The modified niche model: Including detritus in simple structural food web models. - Ecol. Modell. 208: 9-16.

Hashmi, D. and Causey, D. 2008. A system in which available energy per se controls alpha diversity: marine pelagic birds. - Am. Nat. 171: 419-429.

Hawkins, B. A. et al. 2007. A global evaluation of metabolic theory as an explanation for terrestrial species richness gradients. - Ecology 88: 1877-1888.

Huxham, M. et al. 1996. Do parasites reduce the chances of triangulation in a real food web? - Oikos 76: 284-300.

Jenkins, B. et al. 1992. Productivity, disturbance and food web structure at a local spatial scale in experimental container habitats. - Oikos 65: 249-255.

Kaunzinger, C. M. K. and Morin, P. J. 1998. Productivity controls food-chain properties in microbial communities. - Nature 395: 495-497.

Lafferty, K. D. et al. 2006. Parasites dominate food web links. - Proc. Natl Acad. Sci. USA 103: 11211-11216.

Lafferty, K. D. et al. 2008. Parasites in food webs: the ultimate missing links. - Ecol. Lett. 11: 533-546.

Lindeman, R. L. 1942. The trophic-dynamic aspect of ecology. - Ecology 23: 399-418.

Lopez-Pascua, L. D. C. and Buckling, A. 2008. Increasing productivity accelerates host-parasite coevolution. - J. Evol. Biol. 21: 853-860.

Martinez, N. D. 1993. Effects of resolution on food web structure. - Oikos 66: 403-412.

Monkkonen, M. et al. 2006. Energy availability, abundance, energy-use and species richness in forest bird communities: a test of the species-energy theory. - Global Ecol. Biogeogr. 15: 290-302.

Mouritsen, K. N. and Poulin, R. 2002. Parasitism, community structure and biodiversity in intertidal ecosystems. - Parasitology 124: S101-S117. 
Nakano, S. et al. 1999. Terrestrial-aquatic linkages: riparian arthropod inputs alter trophic cascades in a stream food web. - Ecology 80: 2435-2441.

Pascual, M. and Dunne, J. A. 2004. From small to large ecological networks in a dynamic world. - In: Pascual, M. and Dunne, J. A. (eds), Workshop on 'From structure to dynamics in complex ecological networks', pp. 3-24.

Pimm, S. L. 1982. Food webs. - Chapman and Hall.

Poulin, R. 2007a. Are there general laws in parasite ecology? - Parasitology 134: 763-776.

Poulin, R. 2007b. Evolutionary ecology of parasites. - Princeton Univ. Press.

Poulin, R. and Rohde, K. 1997. Comparing the richness of metazoan ectoparasite communities of marine fishes: controlling for host phylogeny. - Oecologia 110: 278-283.

Poulin, R. and Morand, S. 2000. The diversity of parasites. - Q. Rev. Biol. 75: 277-293.

Schmid-Araya, J. M. and Schmid, P. E. 2000. Trophic relationships: integrating meiofauna into a realistic benthic food web. - Freshwater Biol. 44: 149-163.

Thieltges, D. W. et al. 2011. Food web including metazoan parasites for a tidal basin in Germany and Denmark. - Ecology 92: 2005.

Thompson, R. M. and Townsend, C. R. 2000. Is resolution the solution?: the effect of taxonomic resolution on the calculated

Supplementary material (available online as Appendix oik00245 at $<$ www.oikosoffice.lu.se/appendix $>$ ). Appendix 1 . properties of three stream food webs. - Freshwater Biol. 44: 413-422.

Thompson, R. M. and Townsend, C. R. 2005a. Energy availability, spatial heterogeneity and ecosystem size predict food-web structure in streams. - Oikos 108: 137-148.

Thompson, R. M. and Townsend, C. R. 2005b. Food-web topology varies with spatial scale in a patchy environment. - Ecology 86: 1916-1925.

Thompson, R. M. et al. 2005. Importance of parasites and their life cycle characteristics in determining the structure of a large marine food web. - J. Anim. Ecol. 74: 77-85.

Thompson, R. M. et al. 2007. Trophic levels and trophic tangles: the prevalence of omnivory in real food webs. - Ecology 88: 612-617.

Thompson, R. M. et al. 2012. Food webs: reconciling the structure and function of biodiversity. - Trends Ecol. Evol 27: 689-697.

Wallace, J. B. et al. 1997. Multiple trophic levels of a forest stream linked to terrestrial litter inputs. - Science 277: 102-104.

Warren, P. H. and Weatherby, A. J. 2006. Energy input and species diversity patterns in microcosms. - Oikos 113: 314-324.

Williams, R. J. and Martinez, N. D. 2004. Limits to trophic levels and omnivory in complex food webs: theory and data. - Am. Nat. 163: 458-468. 